\title{
Effect of alginate and chitosan on viability and release behavior of Bifidobacterium pseudocatenulatum G4 in simulated gastrointestinal fluid
}

\begin{abstract}
The main aim of this study was to investigate the effect of different coating materials (i.e. Naalginate and chitosan) on the viability and release behavior of Bifidobacterium pseudocatenulatum G4 in the simulated gastric fluid (SGF) and simulated intestinal fluid (SIF). This study reports the viability of encapsulated B. pseudocatenulatum G4 coated using different alginate $(2-4 \mathrm{~g} / 100 \mathrm{~mL})$ and chitosan $(0.2-0.8 \mathrm{~g} / 100 \mathrm{~mL})$ concentrations. The results indicated that the highest concentration of alginate $(4.4142 \mathrm{~g} / 100 \mathrm{~mL})$ along with $0.5578 \mathrm{~g} / 100 \mathrm{~mL}$ chitosan resulted in the highest viability of B. pseudocatenulatum G4. The release behavior of the encapsulated probiotics in SGF ( $\mathrm{pH} 1.5)$ in $2 \mathrm{~h}$ followed by $4 \mathrm{~h}$ in SIF (pH 7.4) was also assessed. The resistance rate of alginate-chitosan capsule in SGF was higher than SIF. The alginate-chitosan encapsulated cells had also more resistance than alginate capsules. The current study revealed that alginate encapsulated $B$. Pseudocatenulatum G4 exhibited longer survival than its free cells (control).
\end{abstract}

Keyword: Encapsulation; Chitosan; Alginate; Probiotics; Cell viability; Release behavior 